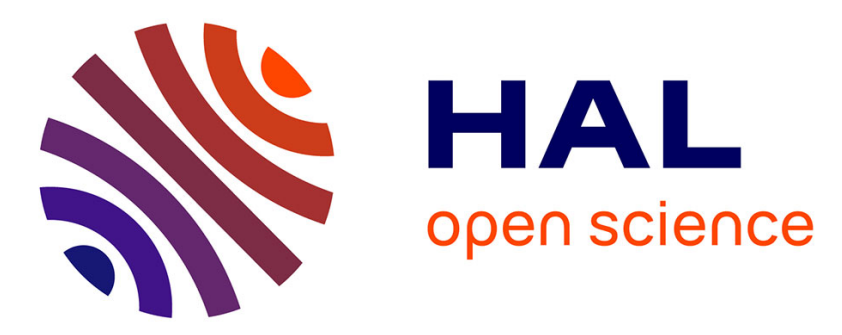

\title{
Stress-dilatancy of natural soft clay under an undrained creep condition
}

\author{
Li-Zhong Wang, Zhen-Yu Yin
}

\section{To cite this version:}

Li-Zhong Wang, Zhen-Yu Yin. Stress-dilatancy of natural soft clay under an undrained creep condition. International Journal of Geomechanics, 2014, 10.1061/(ASCE)GM.1943-5622.0000271 . hal01007332

\section{HAL Id: hal-01007332 \\ https://hal.science/hal-01007332}

Submitted on 22 Feb 2018

HAL is a multi-disciplinary open access archive for the deposit and dissemination of scientific research documents, whether they are published or not. The documents may come from teaching and research institutions in France or abroad, or from public or private research centers.
L'archive ouverte pluridisciplinaire HAL, est destinée au dépôt et à la diffusion de documents scientifiques de niveau recherche, publiés ou non, émanant des établissements d'enseignement et de recherche français ou étrangers, des laboratoires publics ou privés. 


\title{
Stress Dilatancy of Natural Soft Clay under an Undrained Creep Condition
}

\author{
Li-Zhong Wang ${ }^{1}$ and Zhen-Yu Yin ${ }^{2}$
}

\begin{abstract}
The stress-dilatancy relationship is a key point to capture the evolution of both strains and excess pore pressure during an undrained creep of natural soft clay. This paper focuses on investigating the stress dilatancy of natural soft clay during an undrained creep. Undrained triaxial creep tests are performed on $\mathrm{K}_{0}$-consolidated and isotropically consolidated samples of a typical Chinese soft marine clay with different stress levels. A unique stress-dilatancy curve is obtained from all test results. Several typical stress-dilatancy relations for soils are discussed, comparing them with experimental results. A common modification method for the stress dilatancy of sand is adopted and discussed for clay. All comparisons demonstrate that modified dilatancy equations can describe the stress-dilatancy relationship during an undrained creep. The modified dilatancy equation with the inclination of a potential surface seems to better describe the whole trend, and is suitable for natural soft clay.
\end{abstract}

Keywords: Clay; Stress dilatancy; Creep; Triaxial test.

\section{Introduction}

Because of the low permeability of soft clay, an excess pore water pressure is usually generated during the period of construction (e.g., for a high filled embankment, or a foundation for a building), during which foundation soils are deforming simultaneously under undrained conditions. This continuing undrained creep may often result in a collapse of the clay foundation, which implies that the undrained shear strength can be significantly reduced with time, as investigated through undrained triaxial creep tests by various researchers (Casagrande and Wilson 1951; Walker 1969; Holzer et al. 1973; Vaid and Campanella 1977; Adachi and Oka 1982; Yin et al. 2002; Hinchberger and Rowe 2005; Yin and Hicher 2008; Yin et al. 2010b, c, 2011; Yin and Karstunen 2011; Desai et al. 2011; Taechakumthorn and Rowe 2012). Therefore, it is important to capture the undrained-creep behavior to estimate the long-term stability of geotechnical structures.

During an undrained creep, the generation of excess pore pressure reflects the diminution of effective stresses and increase of the stress ratio $q / p^{\prime}$ (i.e., deviatoric stress over mean effective stress) toward the critical state line, which in turn increases the deviatoric strain. Thus, the stress dilatancy is a key point to accurately describe the undrained creep behavior (the evolution of both strains and excess pore pressure with time) of clay.

The focus in this paper is on investigating the stress-dilatancy relationship of natural soft clay during an undrained creep. For this purpose, undrained triaxial creep tests are performed on a typical Chinese soft marine clay. Classical stress-dilatancy relations for soils are discussed, comparing them with experimental results.

\footnotetext{
${ }^{1}$ Professor, Institute of Geotechnical Engineering, Zhejiang Univ., Hangzhou 310027, China. E-mail: wanglz@zju.edu.cn

${ }^{2}$ Associate Professor, Dept. of Civil Engineering, Institute GeM (UMR 6183 CNRS), LUNAM Univ., Ecole Centrale de Nantes, 44321 Nantes, France; Guest Professor, Dept. of Civil Engineering, Shanghai Jiao Tong Univ., Shanghai 200240, China (corresponding author). E-mail: zhenyu .yin@gmail.com.
}

Modifications on dilatancy equations are discussed for anticipating the behavior of clay under an undrained creep condition.

\section{Undrained Triaxial Creep Tests}

\section{Soil Properties}

Undrained triaxial creep tests were carried out on a typical Chinese soft marine clay, Wenzhou clay deposited on the southeast coast of China. A relative homogenous layer of Wenzhou clay from 10.5 to $11.5 \mathrm{~m}$ was selected for sampling. Some basic physical and mechanical properties of Wenzhou clay are summarized in Table 1 . A conventional undrained triaxial test was first performed on a $K_{0}$-consolidated clay sample with a vertical stress of up to two times the preconsolidation pressure ( $p_{0}^{\prime}=105 \mathrm{kPa}, q_{0}=67 \mathrm{kPa}$ with a duration of 2 days before shearing). The peak deviatoric stress $q_{\text {peak }}$ was obtained equal to $92.2 \mathrm{kPa}$.

\section{Test Program and Results}

Natural soft clay is usually deposited under a $K_{0}$-consolidated condition. Additional loads are usually added during constructions, which causes the creeping of soil. A series of undrained triaxial creep tests were performed on identical $K_{0}$-consolidated clay samples under different deviatoric stress levels with stress ratios $q / q_{\text {peak }}$ varying from 0.88 to 1.0 (see Table 2). Fig. 1 presents the evolution of axial strain $\left(\varepsilon_{\mathrm{a}}\right)$ with time and the evolution of excess pore pressure $(\Delta u)$ with time during an undrained creep. Both the axial strain and the excess pore pressure develop with time, and their rates are faster for a higher deviatoric stress level.

Furthermore, four undrained creep tests on isotropically consolidated clay samples ( $p_{0}^{\prime}=105 \mathrm{kPa}$ ) were also performed under four deviatoric stress levels (see Table 2). Fig. 2 shows the similar trend of evolution for both axial strain and excess pore pressure compared with tests under $K_{0}$-consolidated samples.

\section{Stress Dilatancy during an Undrained Creep}

\section{Typical Stress-Dilatancy Relations for Soils}

The physical manifestation of dilatancy was first discussed long ago by Reynolds (1885). Later on, Rowe (1962) and Roscoe et al. (1963) 
introduced two different forms of stress dilatancy equations for soils, based on which various constitutive models have been developed.

Rowe (1962) developed a stress dilatancy equation using the assumption that the ratio of the input energy increment $\sigma_{a} d \varepsilon_{d}^{p}$ to the output energy increment $2 \sigma_{r} d \varepsilon_{r}^{p}$ is a constant, denoted as $K$

$$
\sigma_{a} / \sigma_{r}=K\left(1-d \varepsilon_{v}^{p} / d \varepsilon_{d}^{p}\right)
$$

Eq. (1a) can be rearranged in terms of variables used in critical state soil mechanics, given as

Table 1. Physical and Mechanical Properties of Wenzhou Clay

\begin{tabular}{lccccccc}
\hline$\gamma\left(\mathrm{kN} / \mathrm{m}^{3}\right)$ & $w(\%)$ & $w_{L}(\%)$ & $w_{P}(\%)$ & $e_{0}$ & $\kappa$ & $M$ & $\sigma_{v 0}^{\prime}(\mathrm{kPa})$ \\
\hline 15.5 & 67.5 & 63.4 & 27.6 & 1.89 & 0.042 & 1.25 & 75.4
\end{tabular}

Note: $e_{0}=$ initial void ratio; $M=$ slope of critical state line; $w=$ water content; $w_{L}=$ liquid limit; $w_{P}=$ plastic limit; $\gamma=$ unit weight; $\kappa=$ swelling coefficient; $\sigma_{v 0}^{\prime}=$ preconsolidation pressure.

Table 2. List of Undrained Triaxial Creep Tests on Wenzhou Clay

\begin{tabular}{lclc}
\hline & $\begin{array}{c}w(\%) \\
\text { Test }\end{array}$ & \multicolumn{1}{c}{ Sample condition } & $\begin{array}{c}\text { Loading } \\
\text { condition } \\
(\Delta q)(\mathrm{kPa})\end{array}$ \\
\hline CAUCreep-1 & 51.5 & $K_{0}$-consolidated at & 12.6 \\
CAUCreep-2 & 50.5 & $p_{0}^{\prime}=105 \mathrm{kPa}, q_{0}=67 \mathrm{kPa}$ & 16.8 \\
CAUCreep-3 & 51.2 & & 20.5 \\
CAUCreep-4 & 51.1 & & 25.2 \\
CIUCreep-1 & 54.6 & Isotropically consolidated at & 60.9 \\
CIUCreep-2 & 54.9 & $p_{0}^{\prime}=105 \mathrm{kPa}, q_{0}=0 \mathrm{kPa}$ & 65.1 \\
CIUCreep-3 & 54.7 & & 69.3 \\
CIUCreep-4 & 55.1 & & 75.6 \\
\hline
\end{tabular}

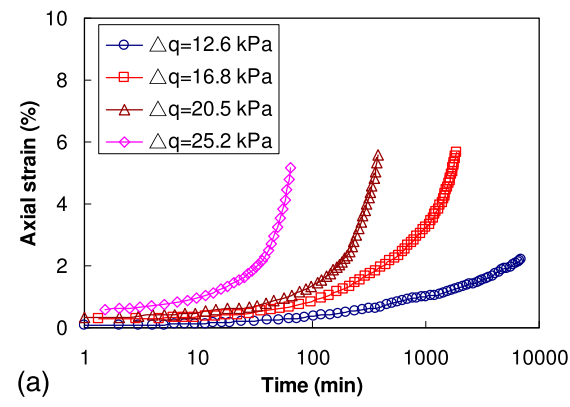

Fig. 1. Undrained triaxial creep tests on $K_{0}$-consolidated samples: (a) axial strain versus time; (b) excess pore pressure versus time
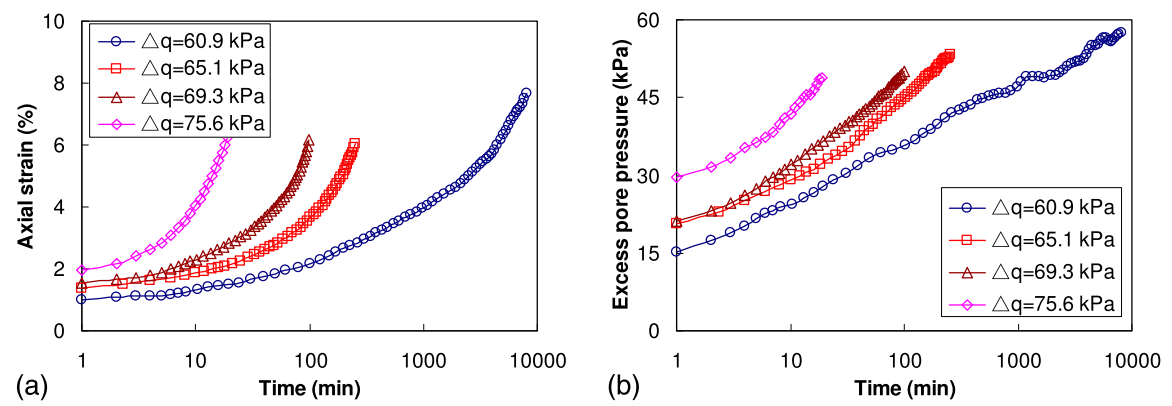

Fig. 2. Undrained triaxial creep tests on isotropically consolidated samples: (a) axial strain versus time; (b) excess pore pressure versus time where $\eta=$ stress ratio of deviatoric stress to mean effective stress $q / p^{\prime} ; M=$ slope of critical state line in $p^{\prime}-q$ plan; $p^{\prime}=\left(\sigma_{a}+2 \sigma_{r}\right) / 3$ $=$ mean effective stress; $q=\sigma_{a}-\sigma_{r}=$ deviatoric stress; $d \varepsilon_{v}^{p}=d \varepsilon_{a}^{p}$ $+2 d \varepsilon_{r}^{p}=$ volumetric strain increment; $d \varepsilon_{d}^{p}=2\left(d \varepsilon_{a}^{p}+2 d \varepsilon_{r}^{p}\right) / 3$ $=$ deviatoric strain increment; and subscripts $a$ and $r=$ axial and radial directions, respectively, in a triaxial setup. The superscript $p$ denotes plastic components.

In a later work, Roscoe et al. (1963) proposed a dilatancy equation based on the principle of energy dissipation under triaxial condition, which stated that the plastic input work is equal to the dissipated energy in friction

$$
p^{\prime} d \varepsilon_{v}^{p}+q d \varepsilon_{d}^{p}=M p^{\prime} d \varepsilon_{d}^{p}
$$

where Eq. (2a) can be rearranged to the form of dilatancy equation

$$
d \varepsilon_{v}^{p} / d \varepsilon_{d}^{p}=M-q / p
$$

This dilatancy equation reflects the flow rule of the original Cam clay model developed by Schofield and Wroth (1968).

Another widely used stress dilatancy equation has been proposed with the development of the Modified Cam clay model by Roscoe and Burland (1968). The dilatancy equation can be expressed under a triaxial condition

$$
d \varepsilon_{v}^{p} / d \varepsilon_{d}^{p}=\frac{M^{2}-\eta^{2}}{2 \eta}
$$

Based on this, various constitutive models have been developed. For instance, the inclined yield and potential surfaces have been generally accepted for constitutive models accounting for the feature

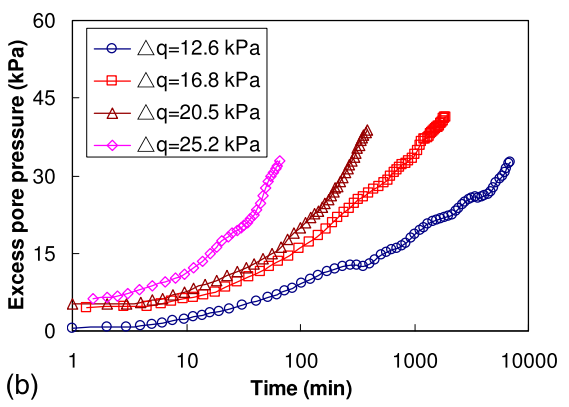

(b) 
of anisotropy (e.g., Dafalias 1987; Hashiguchi and Chen 1998; Asaoka et al. 2002; Ling et al. 2002; Wheeler et al. 2003; Yin et al. 2010b, 2011). The dilatancy equation can be generally expressed as follows:

$$
d \varepsilon_{v}^{p} / d \varepsilon_{d}^{p}=M^{2}-\eta^{2} / 2(\eta-\alpha)
$$

where $\alpha=$ inclination of yield or potential surface in $p^{\prime}-q$ plan. The initial value can be estimated by $\alpha_{K_{0}}=\left(\eta_{K_{0}}^{2}+3_{\eta_{K_{0}}}-M^{2}\right) / 3$ for $K_{0}$-consolidated clays (see Wheeler et al. 2003). For $\alpha=0$, Eq. (4) can be reduced to Eq. (3).

\section{Stress Dilatancy of a $K_{0}$-Consolidated Sample}

The undrained triaxial condition implies a null volumetric strain $\left(d \varepsilon_{a}+2 d \varepsilon_{r}=0\right)$. Thus, during an undrained creep, the incremental deviatoric strain can be obtained

$$
d \varepsilon_{d}=2 / 3\left(d \varepsilon_{a}-d \varepsilon_{r}\right)=d \varepsilon_{a}
$$

Because of the null change of the deviatoric stress during an undrained creep test, the elastic deviatoric strain is null. Therefore, Eq. (5) can be used for the incremental plastic deviatoric strain, based on which the evolution of $d \varepsilon_{d}^{p}$ with time in Fig. 3(a) was obtained from Fig. 1(a).

Furthermore, the null volumetric strain condition also implies the relationship $d \varepsilon_{v}^{p}=-d \varepsilon_{v}^{e}$ between plastic and elastic volumetric strains; thus, the increment of plastic volumetric strain can be obtained by the change of mean effective stress from the generation of excess pore pressure $\left(d p^{\prime}=-d u\right)$, as follows:

$$
d \varepsilon_{v}^{p}=d u / K
$$

with the bulk modulus $K=\left(1+e_{0}\right) p^{\prime} / \kappa$ and $p^{\prime}=p_{0}+\Delta q / 3-\Delta u$. Therefore, the evolution of both $d \varepsilon_{v}^{p}$ and stress ratio $q / p^{\prime}$ with time in Figs. 3(b and c) was obtained from Fig. 1(b).

Therefore, the stress-dilatancy relationship can be plotted in Fig. 3(d) for all creep tests, which demonstrates a unique relationship for different deviatoric stress levels. In Fig. 3(d), four different dilatancy equations [Eqs. (1)-(4)] were also plotted, which shows that the dilatancy equation by Rowe (1962) and that by Roscoe et al. (1963) can better describe the stress dilatancy behavior of undrainedcreep tests on $K_{0}$-consolidated samples.

\section{Stress Dilatancy of an Isotropically Consolidated Sample}

Similar to the previous section, the evolution of $d \varepsilon_{d}^{p}, d \varepsilon_{v}^{p}$, and $q / p^{\prime}$ with time in Figs. 4(a-c) were obtained from the evolutions of axial strain and excess pore pressure in Figs. 2(a and b). Thus, the stressdilatancy relationship was plotted in Fig. 4(d) for all four tests on isotropically consolidated samples. The stress-dilatancy relationship from tests on $K_{0}$-consolidated samples was also plotted in this figure, which demonstrates a unique relationship for different deviatoric stress levels and different consolidation conditions. Again, in Fig. 4(d) four typical dilatancy equations [Eqs. (1)-(4)] were also plotted, which shows that the dilatancy equation by Rowe (1962) and that by Roscoe et al. (1963) can also better describe the stress dilatancy behavior of undrained creep tests on isotropically consolidated samples.
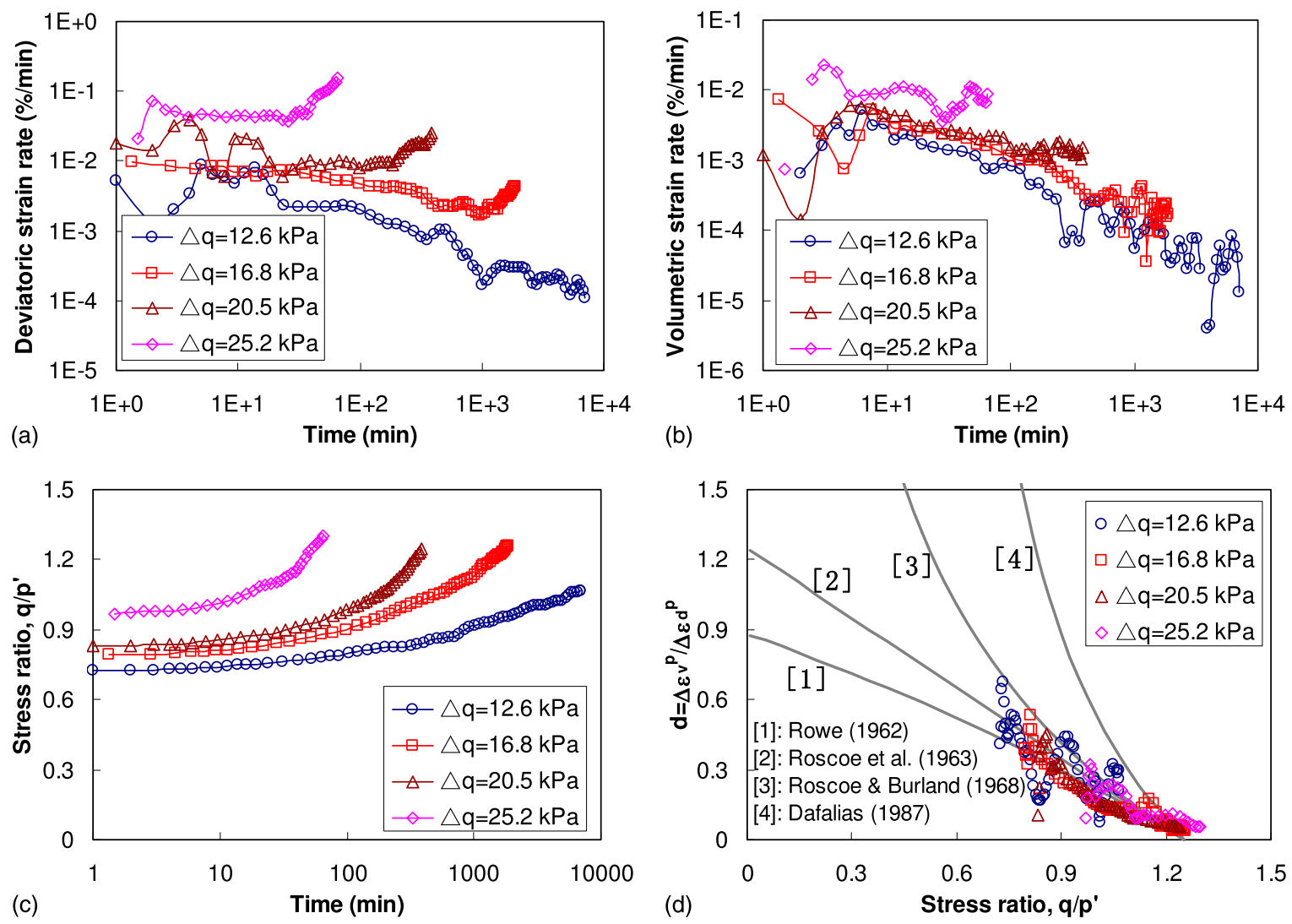

Fig. 3. Undrained triaxial creep tests on $K_{0}$-consolidated samples: (a) plastic deviatoric strain rate versus time; (b) plastic volumetric strain rate versus time; (c) stress ratio versus time; (d) ratio of plastic strain increment versus stress ratio 


\section{Modification of the Stress Dilatancy Equation}

Because of the discrepancy in fitting experimental tests, a material constant $D$ is often introduced in dilatancy equations for sand, such as that proposed by Jefferies (1993), Gajo and Muir Wood (1999), Yin et al. (2010a), and Yin and Chang (2012)

$$
d \varepsilon_{v}^{p} / d \varepsilon_{d}^{p}=D \times f(M, \eta)
$$

If the constant $D$ is introduced in Eqs. (1)-(4), different values of $D$ can be obtained based on the best curve fitting shown in Fig. 5(a). Because of the modification, the difference between four stressdilatancy functions in Fig. 4(d) becomes slight within the zone of test data, while for low stress ratio the difference is still significant. Based on comparisons with available test data, it can be pointed out that all modified equations can describe the stress-dilatancy relationship during an undrained creep. Although the test data are located in a limited zone with the stress ratio $\eta$ superior to 0.65 , the modified dilatancy equation implied by Eq. (4) seems to better describe the whole trend. The constant $D$ can be determined from tests on either $K_{0}$-consolidated samples or isotropically consolidated samples.

If the evolution of inclination $\alpha$ during shearing (namely induced anisotropy) by Wheeler et al. (2003) is accepted as

$$
d \alpha=\mu\left[(3 \eta / 4-\alpha)\left\langle d \varepsilon_{v}^{p}\right\rangle+\beta(\eta / 3-\alpha) d \varepsilon_{d}^{p}\right]
$$

then the dilatancy curve by the modified Eq. (4) varies from $\alpha$ $=\alpha_{K 0}$ to $M / 3$ because of the dominant deviatoric straining during
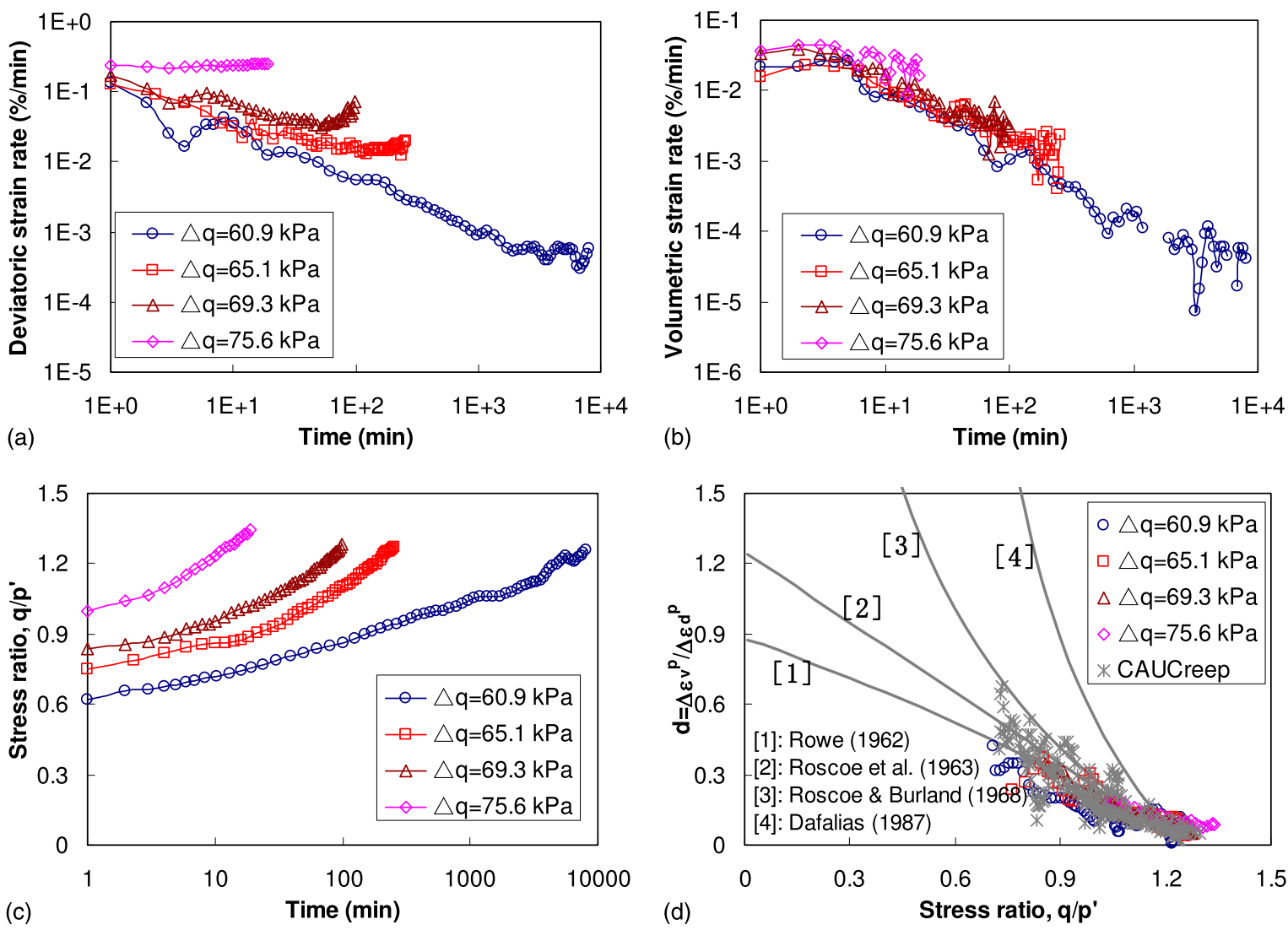

Fig. 4. Undrained triaxial creep tests on isotropically consolidated samples: (a) plastic deviatoric strain rate versus time; (b) plastic volumetric strain rate versus time; (c) stress ratio versus time; (d) ratio of plastic strain increment versus stress ratio
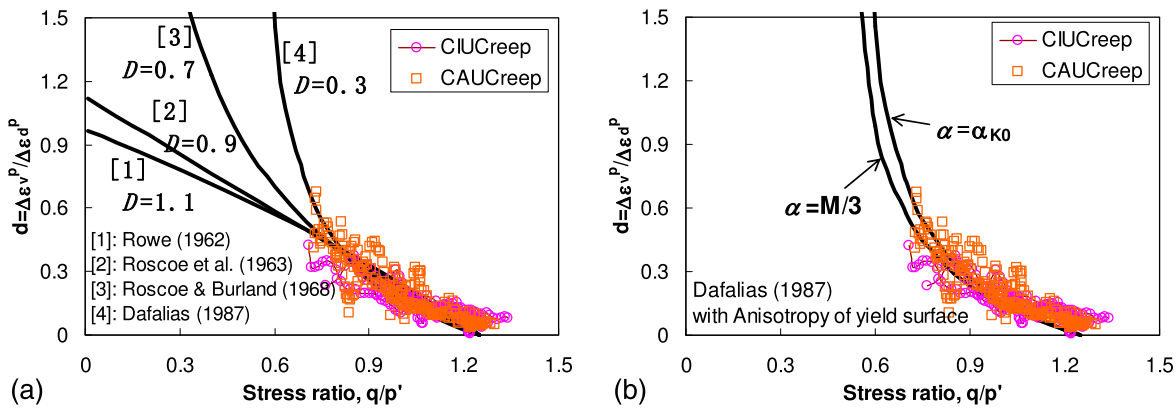

Fig. 5. Stress-dilatancy curves: (a) comparison with different modified dilatancy equations; (b) comparison with the modified dilatancy accounting for induced anisotropy 
an undrained creep, shown in Fig. 5(b), which is suitable according to experimental results.

\section{Conclusions}

Undrained triaxial creep tests were performed on $K_{0}$-consolidated and isotropically consolidated samples of a typical Chinese soft marine clay. A unique stress-dilatancy relationship was obtained from all tests. Four typical stress-dilatancy relations such as dilatancy equations by Rowe (1962), Roscoe et al. (1963), Roscoe and Burland (1968), and Dafalias (1987) were discussed comparing to experimental results. Comparisons show that the dilatancy equation by Rowe (1962) and that by Roscoe et al. (1963) can better describe the stress dilatancy behavior of undrained creep tests.

A common modification method for the stress dilatancy of sand was applied to the stress dilatancy of clay during an undrained creep. All comparisons demonstrate that four modified dilatancy equations can describe the stress-dilatancy relationship during an undrained creep. The modified dilatancy equation with the inclination of potential surface seems to better describe the whole trend, and is suitable for natural soft clay.

Future works on numerical modeling will be carried out on the application of the stress dilatancy to soft soils.

\section{Acknowledgments}

This research was financially supported by the National Natural Science Foundation of China (grant Nos. 41240024 and 41372285), the Research on Key Technology of Large-Span Municipal Tunnel Construction and Operation under Complicated Environment Project by the Research Fund for the Doctoral Program of Higher Education of China (grant No. 20110073120012), the Shanghai Pujiang Talent plan (grant No. 11PJ1405700), and the European project CREEP (grant No. PIAPP-GA-2011-286397). This support is greatly appreciated. In addition, the authors thank the first author's former Ph.D. student, Mr. Hanbo Dan, for carrying out laboratory tests.

\section{References}

Adachi, T., and Oka, F. (1982). "Constitutive equations for normally consolidated clay based on elasto-viscoplasticity." Soils Found., 22(4), 57-70.

Asaoka, A., Noda, T., Yamada, E., Kaneda, K., and Nakano, M. (2002). “An elasto-plastic description of two distinct volume change mechanisms of soils." Soils Found., 42(5), 47-57.

Casagrande, A., and Wilson, S. (1951). "Effect of rate of loading on strength of clays and shales at constant water content." Geotechnique, 2(3), 251-263.

Dafalias, Y. F. (1987). "Anisotropic critical state clay plasticity model." Proc., 2nd Int. Conf. on Constitutive Laws for Engineering Materials, Vol. 1, Elsevier, New York, 513-521.

Desai, C. S, Sane, S., and Jenson, J. (2011). "Constitutive modeling including creep- and rate-dependent behavior and testing of glacial tills for prediction of motion of glaciers." Int. J. Geomech., 10.1061/(ASCE) GM.1943-5622.0000091, 465-476.

Gajo, A., and Muir Wood, D. (1999). "Severn-Trent sand: A kinematic hardening constitutive model: The $q-p$ formulation." Geotechnique, 49(5), 595-614.
Hashiguchi, K., and Chen, Z.-P. (1998). "Elastoplastic constitutive equations of soils with the subloading surface and the rotational hardening." Int. J. Numer. Anal. Methods Geomech., 22(3), 197-227.

Hinchberger, S. D., and Rowe, R. K. (2005). "Evaluation of the predictive ability of two elastic-viscoplastic constitutive models." Can. Geotech. J., 42(6), 1675-1694.

Holzer, T. L., Hoeg, K., and Arulanandan, K. (1973). "Excess pore pressures during undrained clay creep." Can. Geotech. J., 10(1), 12-24.

Jefferies, M. G. (1993). "Nor-Sand: A simple critical state model for sand." Geotechnique, 43(1), 91-103.

Ling, H. I., Yue, D., Kaliakin, V. N., and Themelis, N. J. (2002). "Anisotropic elastoplastic bounding surface model for cohesive soils." J. Eng. Mech., 10.1061/(ASCE)0733-9399(2002)128:7(748), 748-758.

Reynolds, O. (1885). "On the dilatancy of media composed of rigid particles in contact. With experimental illustrations." Philos. Mag., 20(127), $469-481$.

Roscoe, K. H., and Burland, J. B. (1968). "On the generalized stress-strain behavior of 'wet' clay." Engineering plasticity, Cambridge University Press, Cambridge, MA, 553-609.

Roscoe, K. H., Schofield, A. N., and Thurairajah, A. (1963). "Yielding of clays in states wetter than critical." Geotechnique, 13(3), 211-240.

Rowe, P. W. (1962). "The stress-dilatancy relations for static equilibrium of an assembly of particles in contact." Proc. R. Soc. Lond. A, 269(1339), 500-527.

Schofield, A. N., and Wroth, C. P. (1968). Critical state soil mechanics, McGraw Hill, Maidenhead, U.K.

Taechakumthorn, C., and Rowe, R. K. (2012). "Performance of reinforced embankments on rate-sensitive soils under working conditions considering effect of reinforcement viscosity." Int. J. Geomech., 10.1061/ (ASCE)GM.1943-5622.0000094, 381-390.

Vaid, Y. P., and Campanella, R. G. (1977). "Time-dependent behavior of undisturbed clay." J. Geotech. Engrg. Div., 103(7), 693-709.

Walker, L. K. (1969). "Undrained creep in a sensitive clay." Geotechnique, 19(4), 515-529.

Wheeler, S. J., Naatanen, A., Karstunen, M., and Lojander, M. (2003). "An anisotropic elastoplastic model for soft clays." Can. Geotech. J., 40(2), 403-418.

Yin, J.-H., Zhu, J.-G., and Graham, J. (2002). "A new elastic viscoplastic model for time-dependent behaviour of normally and overconsolidated clays: Theory and verification." Can. Geotech. J., 39(1), 157-173.

Yin, Z.-Y., and Chang, C. S. (2012). "Stress-dilatancy behavior for sand under loading and unloading conditions." Int. J. Numer. Anal. Meth. Geomech., 37(8), 855-870.

Yin, Z.-Y., Chang, C. S., and Hicher, P.-Y. (2010a). "Micromechanical modelling for effect of inherent anisotropy on cyclic behaviour of sand." Int. J. Solids Struct., 47(14-15), 1933-1951.

Yin, Z.-Y., Chang, C. S., Karstunen, M., and Hicher, P.-Y. (2010b). "An anisotropic elastic-viscoplastic model for soft soils." Int. J. Solids Struct., 47(5), 665-677.

Yin, Z.-Y., and Hicher, P.-Y. (2008). "Identifying parameters controlling soil delayed behaviour from laboratory and in situ pressuremeter testing." Int. J. Numer. Anal. Methods Geomech., 32(12), 1515-1535.

Yin, Z.-Y., and Karstunen, M. (2011). "Modelling strain-rate-dependency of natural soft clays combined with anisotropy and destructuration." Acta Mech. Solida Sin., 24(3), 216-230.

Yin, Z.-Y., Karstunen, M., Chang, C. S., Koskinen, M., and Lojander, M. (2011). "Modeling time-dependent behavior of soft sensitive clay." J. Geotech. Geoenviron. Eng., 10.1061/(ASCE)GT.1943-5606.0000527, 1103-1113.

Yin, Z.-Y., Karstunen, M., and Hicher, P.-Y. (2010c). "Evaluation of the influence of elasto-viscoplastic scaling functions on modelling timedependent behaviour of natural clays.” Soils Found., 50(2), 203-214. 